\title{
Hippocampal GLP-I Receptors Influence Food Intake, Meal Size, and Effort-Based Responding for Food through Volume Transmission
}

\author{
Ted M Hsu ${ }^{1,2}$, Joel D Hahn², Vaibhav R Konanur ${ }^{2}$, Ashley Lam' and Scott E Kanoski*, ${ }^{*, 2}$ \\ 'Neuroscience Program, University of Southern California, Los Angeles, CA, USA; ${ }^{2}$ Department of Biological Sciences, University of Southern \\ California, Los Angeles, CA, USA
}

\begin{abstract}
Glucagon-like peptide-I (GLP-I) is produced in the small intestines and in nucleus tractus solitarius (NTS) neurons. Activation of central GLP-I receptors (GLP-IRs) reduces feeding and body weight. The neural circuits mediating these effects are only partially understood. Here we investigate the inhibition of food intake and motivated responding for food in rats following GLP-IR activation in the ventral hippocampal formation (HPFv), a region only recently highlighted in food intake control. Increased HPFv GLP-IR activity following exendin-4 administration potently reduced food intake (both chow and Western diet) and body weight, whereas HPFv GLP-IR blockade increased food intake. These hypophagic effects were based on reduced meal size, and likely do not involve nausea as HPFv exendin-4 did not induce a conditioned flavor avoidance. HPFv GLP-IR activation also reduced effort-based responding for food under an operant progressive ratio reinforcement schedule, but did not affect food conditioned place preference expression. To investigate possible routes of HPFv GLP-I signaling, immunohistochemical analysis revealed the absence of GLP-I axon terminals in the HPFv, suggesting volume transmission as a mechanism of action. Consistent with this, the presence of active GLP-I was detected in both the cerebrospinal fluid (CSF) and the HPFv. The source of CSF GLP-I may be NTS GLP-I-producing neurons, as, (I) 30\% of NTS GLP-I neurons colocalized with the retrograde tracer fluorogold (FG) following lateral ventricle FG injection, and (2) GLP-I-immunoreactive axon terminals were observed adjacent to the ventricular ependymal layer. Collectively these findings illuminate novel neuronal and behavioral mechanisms mediating food intake reduction by GLP-I.
\end{abstract}

Neuropsychopharmacology (20I5) 40, 327-337; doi:I0.1038/npp.2014.175; published online 6 August 2014

\section{INTRODUCTION}

Glucagon-like Peptide-1 (GLP-1) is a hormone synthesized primarily in L-cells of the distal small intestines and from hindbrain neurons in the nucleus tractus solitarius (NTS) (Holst, 2007). Peripheral and central activation of GLP-1 receptors (GLP-1Rs) produces incretin effects (increased insulin secretion) and reduces food intake and body weight (Kanoski et al, 2011a; Ruttimann et al, 2009; Turton et al, 1996; Williams et al, 2009). Investigation of the specific nuclei mediating the food intake inhibitory effects of GLP-1R signaling has mainly focused on hypothalamic (eg, paraventricular and lateral hypothalamus) (McMahon and Wellman, 1998; Schick et al, 2003; Vrang et al, 2007) and hindbrain nuclei (eg, NTS) (Hayes et al, 2011; Kinzig et al, 2002). Recent reports also reveal anorectic effects following GLP-1R activation in mesolimbic pathway nuclei, including

\footnotetext{
*Correspondence: Dr SE Kanoski, Department of Biological Sciences, University of Southern California, 3560 Watt Way, PED 107, Los Angeles, CA 90089-0652, USA, Tel: + 9162138215762 , Fax: +1916213740 6159, E-mail: kanoski@usc.edu

Received 2 May 20।4; revised 5 July 20।4; accepted II July 20।4; accepted article preview online 18 July 2014
}

the ventral tegmental area (VTA) (Alhadeff et al, 2012; Dickson et al, 2012) and nucleus accumbens (Dossat et al, 2011), suggesting that GLP-1R signaling has a role in higherorder, motivational aspects of feeding behavior.

The hippocampal formation (HPF) is classically associated with learning and memory; however, recent studies implicate the HPF in the control of food intake regulation (for reviews, see Davidson et al, 2007, 2005; Kanoski, 2012; Parent et al, 2014; Kanoski et al, 2011b), particularly the 'ventral' (temporal) subregion (HPFv). The adipocyte hormone leptin and the gut-derived peptide ghrelin act on receptors in the HPFv to decrease or increase, respectively, food intake and effort-based responding for palatable food (Kanoski et al, 2013, 2011b). Interestingly, GLP-1Rs are also expressed within the HPF, with the most extensive expression seen in the HPFv (Merchenthaler et al, 1999). GLP-1R activation in the HPF has neuroprotective effects against excitotoxic or beta amyloid-induced neuronal damage in hippocampal neurons (Perry et al, 2002, 2003). Moreover, upregulation of HPF GLP-1R activity increases synaptic plasticity and improves hippocampal-dependent spatial learning (During et al, 2003; McClean et al, 2011). Despite the fact that the GLP-1 system is strongly implicated in anorectic control, the role of HPFv GLP-1R signaling in 
feeding behavior is unknown. Present experiments combine various behavioral strategies with neuropharmacology and biochemistry to examine the hypothesis that GLP-1R activation in HPFv neurons reduces food intake and motivated food-seeking behavior.

Hippocampal GLP-1R signaling has a physiological role in memory function. GLP-1R-deficient mice are impaired in hippocampal-dependent spatial memory, and this impairment is reversible with pharmacological or genetic upregulation of hippocampal GLP-1R signaling (During et al, 2003). The source of the endogenous GLP-1 ligand for HPF GLP-1Rs is unknown given that GLP-1 is produced both in the brain and in the periphery. Here we investigate two potential routes through which GLP-1 may act on HPF GLP1Rs: (1) we evaluate whether GLP-1-immunoreactive (GLP$1-\mathrm{IR}$ ) axon terminals are present in the HPFv (neural transmission), and (2) we explore the possibility that neuronal GLP-1 gains access to the ventricular system and impacts HPFv receptors through volume transmission.

\section{MATERIALS AND METHODS}

\section{Animals and Drugs}

Adult male Sprague-Dawley rats (Charles River Laboratories) (320-450 g body weights (BW)) housed individually in 12-hour dark-light cycle had ad libitum access to chow (LabDiet 5001) and water except where noted. All procedures received approval from the University of Southern California Animal Care and Use Committee.

Volumes for bilateral HPFv injections were $100 \mathrm{nl} / \mathrm{hemi}$ sphere (rate $=5 \mu \mathrm{l} / \mathrm{min}$ ) via 33-gauge injector and microsyringe attached to an infusion pump (Harvard Apparatus), and $1 \mu \mathrm{l}$ for ICV. Injectors were left in place for $30 \mathrm{~s}$ after injections. The GLP-1R agonist, Exendin-4, and the GLP-1R antagonist, Exendin-(9-39) (American Peptide), were dissolved in artificial cerebrospinal fluid (aCSF). Fluorogold (FG; Fluorochrome LLC) was diluted to $2 \%$ in distilled water. Lithium Chloride (LiCl; Sigma-Aldrich) was dissolved in $0.9 \%$ saline.

\section{Cannulae Implantation}

Under ketamine $(90 \mathrm{mg} / \mathrm{kg})$, xylazine $(2.8 \mathrm{mg} / \mathrm{kg})$, and acepromazine $(0.72 \mathrm{mg} / \mathrm{kg})$ anesthesia, 26-guage guide cannulae (Plastics One) were cemented to the skull with jewelers screws and implanted at the following coordinates for HPFv: $-4.9 \mathrm{~mm}$ anterior/posterior, $4.8 \mathrm{~mm}$ medial/ lateral, $6.1 \mathrm{~mm}$ dorsal/ventral; and for lateral cerebroventricular (LV) placement: $-0.9 \mathrm{~m}$ anterior/posterior, $1.8 \mathrm{~mm}$ medial/lateral, $2.6 \mathrm{~mm}$ dorsal/ventral.

Injectors for drug administration projected $2 \mathrm{~mm}$ beyond guide cannula for all injections. Cannula placements for HPFv were assessed postmortem through anatomical verification of the position of $100 \mathrm{nl}$ pontamine sky blue ink (2\%) injections. Only animals with ink confined to the caudal HPFv were included in data analysis. A representative HPFv injection site is shown in Figure 1. The following number of rats were excluded from data analyses based on injection site histology: Exp.1a $(n=3)$, Exp.1b $(n=2)$, Exp.1c $(n=3)$, Exp.1d $(n=1)$, Exp.2a $(n=2)$, Exp.2b $(n=2)$, Exp.3 $(n=0)$.

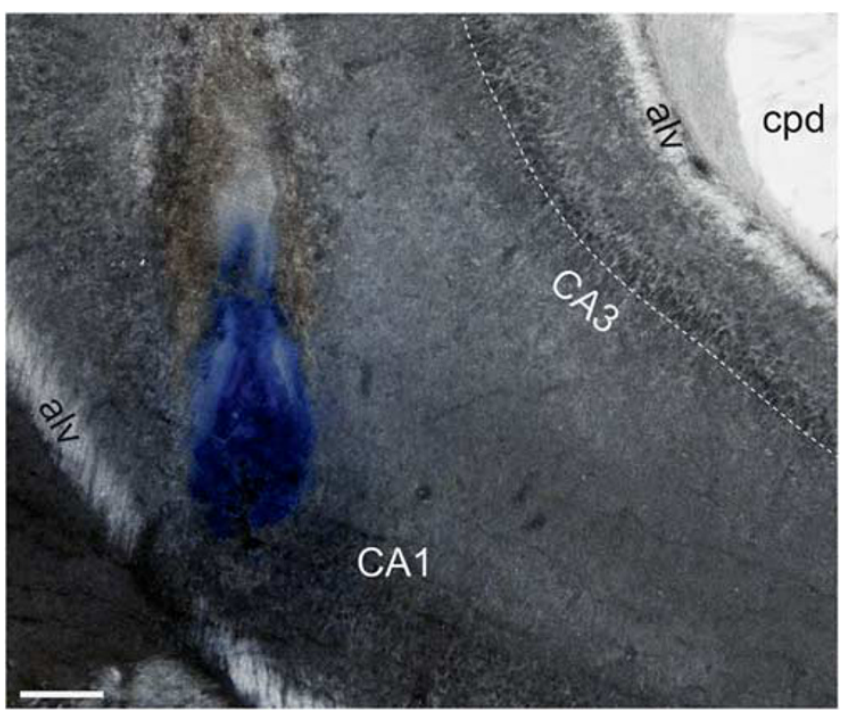

Figure I A representative HPFv injection site is shown as localization of pontamine sky blue ink following a $100 \mathrm{nl}$ injection. Bar $=200 \mu \mathrm{m}$. alv, alveus; cpd, cerebral peduncle. Dashed lined indicates boundary of pyramidal layer of CA3.

Verification of LV injection sites were evaluated 1-week post surgery by measurement of the cytoglucopeniainduced sympatho adrenal-mediated glycemic effect resulting from $210 \mu \mathrm{g}(2 \mu \mathrm{l})$ of 5-thio-D-glucose (Ritter et al, 1981). A postinjection elevation of at least $100 \%$ of baseline glycemia was required for subject inclusion.

\section{Experiment 1: HPFv GLP-1R-Mediated Effects on Food Intake}

Experiment 1a: food intake following HPFv and $L V$ exendin-4. Rats with cannulae targeting the HPFv $(n=10$; avg. $\mathrm{BW}=351 \mathrm{~g})$ received bilateral injections of $0,0.015$, or $0.03 \mu \mathrm{g}$ exendin-4 (total doses: $0 \mu \mathrm{g}, 0.03 \mu \mathrm{g}, 0.06 \mu \mathrm{g}$ ) immediately before lights off. Doses of exendin-4 were based on (Alhadeff et al, 2012; Dickson et al, 2012). In a separate group of rats $(n=12$; avg. $\mathrm{BW}=327 \mathrm{~g})$, the same doses of exendin- 4 were administered to the LV. Treatments were separated by 2-3 days using a counterbalanced withinsubjects design, which allowed sufficient time for treatmentbased body weight losses to return to baseline prior to the next condition. Chow intake was recorded at 1, 3, 6, and $24 \mathrm{~h}$ after injections (spillage accounted for). Body weights were recorded before and $24 \mathrm{~h}$ after injections.

Experiment 1b: meal pattern analysis following HPFv GLP-1R activation. Meal pattern analyses were conducted in chambers equipped with automated food intake monitors (Med Associates). The weight of the food hopper records every $10 \mathrm{~s}$, allowing for ongoing analysis of meal parameters. Animals $(n=13$; avg. $\mathrm{BW}=375 \mathrm{~g})$ were first habituated to the chambers for four consecutive 24-h periods with ad libitum access to chow and water. Bilateral HPFv injections ( 0 or $0.03 \mu \mathrm{g}$ exendin-4) were administered immediately before lights off. The animals were then placed in the chambers for $24 \mathrm{~h}$. Meals were defined as an episode of feeding in which at least $0.25 \mathrm{~g}$ was ingested, with meal 
termination criterion as the beginning of a pause in ingestion of at least $10 \mathrm{~min}$ (Azzara et al, 2002; Kanoski et al, 2013). Data were objectively calculated with a custom Microsoft Excel macro. Treatments were separated by 2-3 days (returned to home cage between treatments) using a counterbalanced within-subjects design.

Experiment 1c: food intake following HPFv GLP-1R antagonist, exendin-(9-39). Rats $(n=9 ;$ avg. $\mathrm{BW}=334 \mathrm{~g})$ received bilateral injections of $0,1.25,2.5$, or $5 \mu \mathrm{g}$ exendin-(9-39) (total doses: $2.5 \mu \mathrm{g}, 5 \mu \mathrm{g}, 10 \mu \mathrm{g}$ ), a selective GLP-1R antagonist, to the HPFv immediately before lights off. Doses of exendin-(9-39) were based on (Alhadeff et al, 2012; Dickson et al, 2012). Treatments were separated by 2-3 days using a counterbalanced within-subjects design. Chow intake and body weight were recorded as described in Experiment 1a.

Experiment 1d: Western diet intake following HPFv exendin-4. Rats $(n=8$; avg. $\mathrm{BW}=420 \mathrm{~g})$ were first habituated to ad libitum access to a choice of a Western diet (41\% kcal fat, Research Diets D12079B) or chow for 2 days prior to testing. Bilateral $\mathrm{HPFv}$ injections (total doses $=0,0.03$, or $0.06 \mu$ g exendin-4) were given immediately before lights off. Treatments were separated by 2-3 days using a counterbalanced within-subjects design. Food intake and body weight were recorded as described in Experiment 1a.

\section{Experiment 2: HPFv GLP-1R-Mediated Effects on Food-Motivated Behavior}

Experiment 2a: operant responding for food (progressive ratio $(P R)$ reinforcement schedule). Animals ( $n=13$; avg. $\mathrm{BW}=406 \mathrm{~g}$ ) were given operant lever press training for food reinforcement as previously described (Kanoski et al, 2014). Briefly, training occurred over 6 days with a 1-h session each day in conditioning boxes (Med Associates) using $45 \mathrm{mg}$ pellet (35\% kcal fat enriched with sucrose, F05989, Bio-Serv) as reinforcers. The first two days used a fixed ratio-1 autoshaping procedure where a pellet dispensed every $600 \mathrm{~s}$ that elapsed without operant-based reinforcement; the next 2 days were FR1 without autoshaping, followed by 2 days of FR3 training. For all procedures, the right lever was the 'active' lever; a left 'inactive' lever served as a dummy lever.

The rats were given two tests (within-subjects design, 2 days intervened) using a PR reinforcement schedule. Bilateral HPFv injections ( 0 or $0.03 \mu \mathrm{g}$ exendin-4; order counterbalanced) were given $3 \mathrm{~h}$ before each test session. The response requirement of the $\mathrm{PR}$ schedule increased progressively as previously described using the following formula: $F(i)=5 e^{\wedge} 0.2 i-5$, where $F(i)$ is the number of lever presses required for next pellet at $\mathrm{i}=$ pellet number. The breakpoint for each animal was defined as the final completed lever press requirement that preceded a 20 -min period without earning a reinforcer.

Experiment 2b: conditioned place preference (CPP). All CPP training and testing procedures are described elsewhere in detail (Kanoski et al, 2014). Briefly, the apparatus had two conjoined plexiglass compartments with a guillotine door in the center (Med Associates). The two sides (henceforth referred to as contexts) were distinguished by wall color and floor texture. Rats $(n=16$; avg. BW $=395 \mathrm{~g})$ were first given one 15 -min habituation session with the guillotine door opened and a video recording the amount of time the animals spent in each of the two contexts. For each rat, the context that was least preferred during habituation was designated as the food-paired context for subsequent training (the preferred context was never paired with food). CPP training consisted of 16, 20-min sessions over 16 days: eight sessions isolated in the food-paired context and eight sessions isolated in the non-food-paired context. During the food-paired sessions, $5 \mathrm{~g}$ of $45 \% \mathrm{kcal}$ high fat/sucrose diet (Research Diets, D12451) were placed on the chamber floor. No food was presented during non-food-paired sessions. All rats consumed the entire $5 \mathrm{~g}$ during each food-paired session. Training order was randomized and pair-matched across groups.

CPP testing occurred 2 days after the last training session using a between-subjects design. Rats were assigned to groups matched for baseline context preference. Three hours prior to the video-recorded testing session, animals received either bilateral $\mathrm{HPFv}$ injections of exendin-4 $(0.03 \mu \mathrm{g})$ or vehicle. During testing, the guillotine door was opened, and the rats were allowed to freely explore the chambers for $15 \mathrm{~min}$. The time spent in each context during the test was later calculated from analysis of video recordings by an experimenter blind to the group assignments and context-food assignments. The dependent variable was the percentage shift in preference for the food-associated context during testing compared with the baseline session.

\section{Experiment 3: HPFv GLP-1R Signaling and Conditioned Flavor Avoidance (CFA)}

For assessment of CFA induced by HPFv exendin-4 (Kinzig et al, 2002) rats (avg. BW $=404 \mathrm{~g}$ ) were assigned to one of two groups based on drug treatment: (1) IP LiCl $0.15 \mathrm{M}$ $(n=9), \quad(2) \quad 0.03 \mu \mathrm{g}$ HPFv exendin-4 $(n=8)$. Food was available ad libitum throughout the experiment. Rats were habituated to a water deprivation schedule for 7 days in which water access was given once daily for 90 min in two water bottles. For training, drug or vehicle treatments were counterbalanced (within-subjects design) across two training days separated by an intervening day. On each training day during the normal $90 \mathrm{~min}$ water access period, rats were given two bottles containing $0.11 \%$ weight/volume unsweetened Kool-Aid and $0.29 \%$ weight/volume saccharin in water. Rats received one novel flavor of Kool-Aid, cherry or grape (equally preferred in rats (Lucas and Sclafani, 1996)), on each training day. Immediately after the 90-min flavor exposure period, one group of rats was given bilateral HPFv injections of exendin- $4(0.03 \mu \mathrm{g})$ or aCSF, whereas the other group received IP $0.15 \mathrm{M} \mathrm{LiCl}(1.33 \mathrm{ml} / 100 \mathrm{~g} \mathrm{BW})$ or saline (flavor/drug pairings counterbalanced). Two days after the second training day, rats were given a two-bottle preference test during the normal $90 \mathrm{~min}$ water access period; one bottle was presented containing the cherry Kool-Aid mix, the other containing the grape Kool-Aid mix. The side (left $v s$ right) of the initial flavor presentation was 
counterbalanced with respect to groups and treatment orders. At 45 and $90 \mathrm{~min}$, fluid intake was recorded (the side of flavor presentation was switched at $45 \mathrm{~min}$ ).

\section{Experiment 4: Lateral ICV FG and Hindbrain GLP-1 Immunohistochemistry}

Four rats (avg. $\mathrm{BW}=352 \mathrm{~g}$ ) received an LV injection of FG. Seven days later, rats were anesthetized and perfused transcardially with $0.9 \%$ saline, followed by $4 \%$ paraformaldehyde in $0.1 \mathrm{M}$ borate buffer. Brains were removed and immersed in fixative containing $12 \%$ sucrose for $20-24 \mathrm{~h}$ at $4{ }^{\circ} \mathrm{C}$. Brains were then frozen in cooled hexane. Transverse sections $(30 \mu \mathrm{m})$ were sliced using a sliding microtome. Sections were stored in KPBS antifreeze solution $(30 \%$ ethylene glycol, $20 \%$ glycerol in $0.02 \mathrm{M}$ potassium phosphate-buffered saline) at $-20{ }^{\circ} \mathrm{C}$ until further processing. One non-ventricular FG-injected rat was processed similarly.

IHC detection of GLP-1 was performed according to the following sequence (overnight incubations rotating at $4{ }^{\circ} \mathrm{C}$ ): (1) Sections were removed from antifreeze and washed in $0.02 \mathrm{M} \mathrm{KPBS}$ (six changes/2 h), (2) KPBS with $0.3 \%$ hydrogen peroxide (15 min), (3) KPBS (three changes), (4) KPBS with $0.3 \%$ Triton X-100 (45 min), (5) KPBS (three changes), (6) KPBS with $2 \%$ donkey serum (10 min), (7) KPBS with $1 \%$ donkey serum, $0.1 \%$ Triton X-100, and rabbit anti-GLP-1 antibodies (1:2000, rabbit anti-GLP-1 (7-37, human), Peninsula Labs). Primary antibody incubation length was $\sim 60 \mathrm{~h}$. (8) KPBS (eight changes in $2 \mathrm{~h}$ ), (9) KPBS with $0.1 \%$ Triton X-100, and biotinylated secondary antibodies (1:1000 biotinylated donkey anti-rabbit, Jackson Immunoresearch; overnight). (10) KPBS (six changes), (11) KPBS with ABC reagent $(1: 1000$, reagent $A$ and $B$ from $A B C$ Elite kit, Vector Labs; 4h), (12) KPBS (three changes), (13) KPBS with $0.005 \% \mathrm{H}_{2} \mathrm{O}_{2}$ and biotinylated tyramine $(1: 1000 ; 10 \mathrm{~min})$, (14) ABC reagent (4h), (15) KPBS (five changes), (16) KPBS with $0.05 \%$ 3,3-diaminobenzidine (DAB; Sigma) and 0.005\% $\mathrm{H}_{2} \mathrm{O}_{2}$ (15 min), (17) KPBS (four changes). Sections were then mounted, dehydrated with ascending concentrations of alcohols solutions, cleared in xylene, and coverslipped with DePex. A Nissl stain was performed on an adjacent collated series of sections to reveal cytoarchitecture.

For IHC detection of GLP-1 in brain sections obtained from the four FG-injected rats, the procedure was identical for steps 1-13; followed by: (14) KPBS with 514 Alexa Fluoravidin (1:800, Invitrogen; overnight), (15) KPBS (three changes). The sections were then mounted, air-dried, and coverslipped. For GLP-1 primary antibody control procedures, the IHC was followed with the primary omitted-this failed to produce any distinct positive immunolabeling. Further, the distribution of positive GLP-1 immunolabeling observed was consistent with previous reports ( $\mathrm{Gu}$ et al, 2013; Larsen et al, 1997). Photomicrographs were taken with a microscope (Nikon 80i)-mounted digital camera, captured under darkfield or fluorescent illumination.

\section{Experiment 5: Detection of Active GLP-1 in Serum, CSF, and the HPFv}

Two separate groups of rats were used to detect active GLP1 in serum, CSF, and HPFv lysates under physiological conditions. For CSF, rats (Group 1; $n=4$; avg. $\mathrm{BW}=331 \mathrm{~g}$ ) were anesthetized following 90-min food restriction during the light cycle and 50-100 $\mu$ l CSF was extracted for each rat from the medullary cisterna magna as described (Pegg et al, 2010). CSF samples were collected in tubes preloaded with $1 \mu \mathrm{l}$ DPP-IV inhibitor (Millipore) and frozen at $-80^{\circ} \mathrm{C}$. Immediately after CSF extraction, animals were decapitated and trunk blood was collected in tubes preloaded with $10 \mu \mathrm{l}$ DPP-IV inhibitor, centrifuged at $15000 \mathrm{rpm}$ for $10 \mathrm{~min}$ to collect serum (stored at $-80{ }^{\circ} \mathrm{C}$ ). Another group of rats (Group 2; $n=7$; avg. $\mathrm{BW}=324 \mathrm{~g}$ ) was anesthetized (same conditions as Group 1) and brains were rapidly removed from the skull after decapitation and placed on a brain matrix (Kopf Instruments) for $2 \mathrm{~mm}$ coronal sectioning. Tissue from the HPFv was rapidly extracted bilaterally from one 2-mm thick section using a 2-mm inner diameter tissue punch. The tissue was flash frozen in cooled isopentane and stored at $-80^{\circ} \mathrm{C}$. Trunk blood was also collected simultaneously during HPFv tissue extraction process. HPFv samples were homogenized in NP-40 buffer. Total protein concentrations for CSF, HPFv lysates, and serum were calculated using the Bradford protein assay. Concentrations for active GLP-1 were detected using a high sensitivity enzyme-linked immunosorbent assay (ELISA; Millipore EZGLPHS-35K), procedures conducted as per the manufacturer's protocols.

\section{Statistical Analysis}

All statistical analyses used repeated measures analysis of variance (ANOVA), except for Experiments 3a (one-way ANOVA), which utilized a between-subjects design. When significant drug main effects were obtained in experiments with more than two treatments, Newman-Keuls post hoc tests were then used to compare individual drug dose treatments with vehicle treatment. The $\alpha$ level for significance was 0.05. Statistical analyses were conducted with computer software (Statistica V7; Statsoft).

\section{RESULTS}

\section{Experiment 1}

Experiment 1a. HPFv Exendin-4 decreased cumulative food intake ( $0.03 \mu \mathrm{g}$ and $0.06 \mu \mathrm{g}$ doses) at 3,6 , and $24 \mathrm{~h}$, and $24 \mathrm{~h}$ delta body weight compared with vehicle injection (Figure 2a) (Drug main effect $\mathrm{Fs}(2,18)>3.6$; p-values $v s$ vehicle $<0.05$ ). The same doses of Exendin-4 delivered to the LV did not significantly impact cumulative food intake or body weight at any time point (Figure $2 \mathrm{~b}$ ) (Drug main effect Fs $(2,22)>1.7)$, although a trend was observed for the $0.06 \mu \mathrm{g}$ dose for $24 \mathrm{~h}$ intake ( $p$-value $<0.07)$. Previous studies show that higher doses of Exendin-4 (eg, $0.2 \mu \mathrm{g}$ ) reduce food intake in rats following ventricular delivery (Hayes et al, 2011, 2008; Shirazi et al, 2013), as does ventricular GLP-1 administration (Kinzig et al, 2002; Williams et al, 2009).

Experiment $1 b$. The $0.03 \mu \mathrm{g}$ dose of Exendin- 4 was chosen for meal pattern analyses and for all other subsequent behavioral assays, as this was the lowest dose to reduce food intake in Experiment 1. Consistent with Experiment 1, HPFv $0.03 \mu \mathrm{g}$ Exendin-4 significantly reduced $24 \mathrm{~h}$ chow 
a

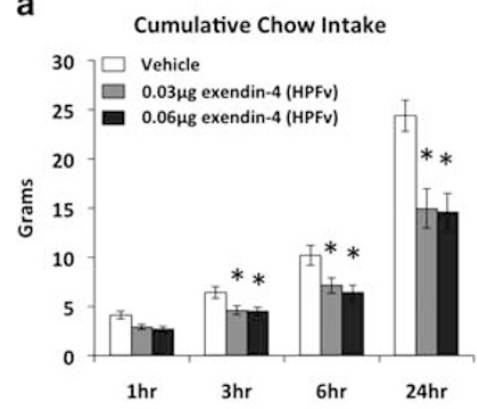

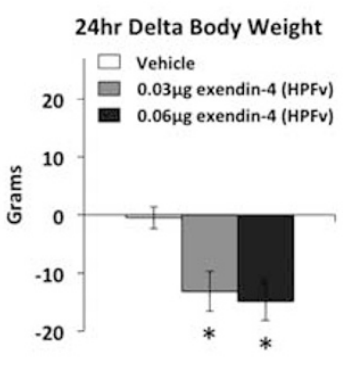

b

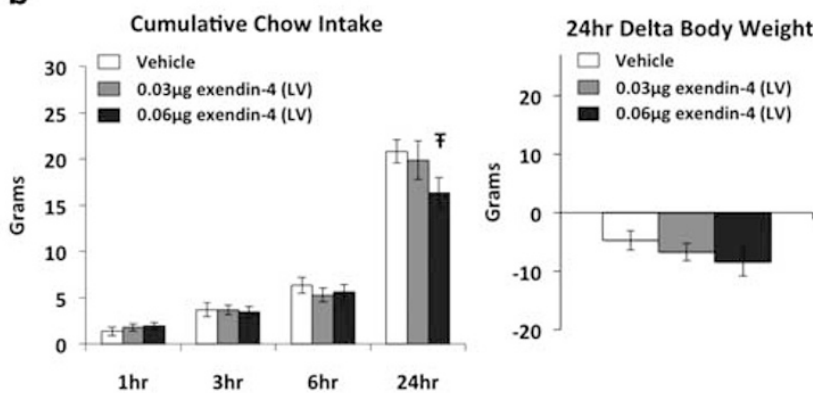

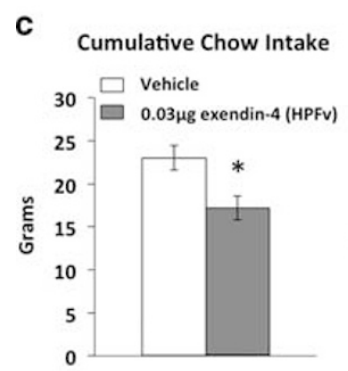
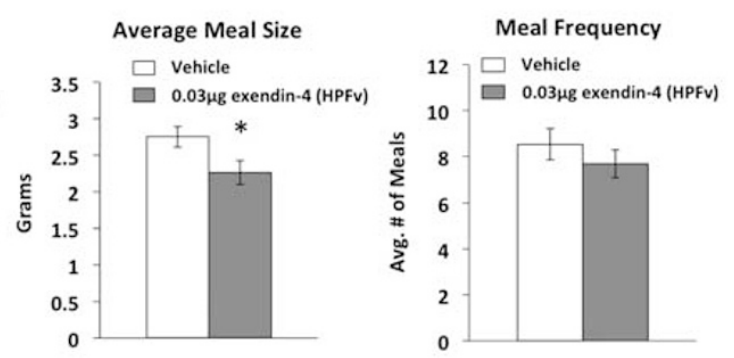

d

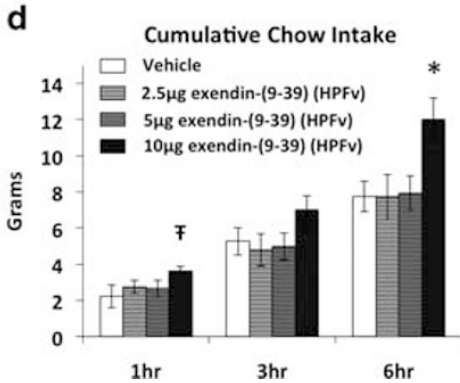

Figure 2 Cumulative chow intake and $24 \mathrm{~h}$ delta body weight following exendin-4 injected in the (a) HPFv, or (b) the rostral LV. (c) Meal pattern analysis following HPFv exendin-4 injections: $24 \mathrm{~h}$ cumulative chow intake, $24 \mathrm{~h}$ average meal size, and $24 \mathrm{~h}$ average meal frequency. (d) Cumulative chow intake following HPFv GLP-IR blockade. Data are mean \pm SEM; ${ }^{\mp} p<0.07, * 0<0.05$ vs vehicle treatment.

intake compared with vehicle treatment (Figure 2c) $(\mathrm{F}(1,12)=9.59, p$-value $<0.01)$. The food intake suppression was accompanied by a significant reduction in average $24 \mathrm{~h}$ meal size $(F(1,12)=9.86, p$-value $<0.01)$ and no significant impact on average meal frequency $(F(1,12)<1.0)$ (Figure 2c). Similar results were obtained during the $12 \mathrm{~h}$ dark cycle (significant reduction in cumulative intake and meal size), whereas no significant treatment effects were found across the $12 \mathrm{~h}$ light cycle (data not shown).

Experiment 1c. $10 \mu \mathrm{g}$ HPFv exendin-(9-39) significantly increased cumulative food intake at $6 \mathrm{~h}$ compared with vehicle (Figure $2 \mathrm{~d})(\mathrm{F}(3,24)=4.39, p$-value $<0.05)$. Cumulative food intake was not significantly influenced by exendin-(9-39) at any other time point (all $\mathrm{Fs}(3,24)<2.2)$, including at $24 \mathrm{~h}$ post injections (data not shown). The mean $24 \mathrm{~h}$ cumulative intake values $( \pm$ SEM) were 21.97 (1.38), 22.33 (2.58), 22.86 (1.41), and 24.37 (1.93) for the 0 , $2.5,5$, and $10 \mu \mathrm{g}$ exendin-(9-39) treatments.

Experiment 1d. When given a choice between ad libitum consumption of a Western diet and chow, 0.03 and $0.06 \mu \mathrm{g}$ HPFv Exendin-4 significantly decreased cumulative Western diet and total kcal intake at 6 and $24 \mathrm{~h}$ compared with vehicle (Figure 3$)(\mathrm{Fs}(2,14)>8.1 ; p$-values $v s$ vehicle $<0.05)$. Interestingly, $0.03 \mu \mathrm{g}$ Exendin-4 significantly increased $24 \mathrm{~h}$ chow intake $(\mathrm{F}(2,14)=3.98, p$-value for $0.03 \mu \mathrm{g} v s$ vehicle $<0.05$ ).

\section{Experiment 2}

Experiment 2a. HPFv Exendin-4 $(0.03 \mu \mathrm{g})$ delivery $3 \mathrm{~h}$ before PR operant testing significantly reduced the total number of active lever presses, as well as the number of pellets earned (Figure 4a) $(\operatorname{Fs}(1,12)>6.39, p$-values $<0.05)$. The number of inactive lever presses was not significantly influenced by Exendin-4 treatment (not shown) $(\mathrm{F}(1,12)=3.38)$.

Experiment 2b. During CPP testing, both the vehicle and Exendin-4 groups demonstrated a significant shift in preference (compared with baseline) for the food-paired context (Figure $4 \mathrm{~b} ; p$-values $<0.05)$. HPFv Exendin-4 $(0.03 \mu \mathrm{g})$ administration $3 \mathrm{~h}$ before CPP testing did not significantly affect the preference shift $(\mathrm{F}(1,14)<1.0)$.

\section{Experiment 3}

As a positive control for the CFA paradigm, we established CFA following IP LiCl treatment, demonstrated as significantly lower intake of the LiCl-paired flavor compared with the vehicle-paired flavor (Figure 4c) $(\mathrm{F}(1,8)=34.05$, $p$-value $<0.001)$. On the other hand, consumption of the HPFv Exendin-4-paired flavor was comparable to the HPFv vehicle-paired flavor; no significant CFA was observed $(\mathrm{F}(1,7)<1.0)$.

\section{Experiment 4}

GLP-1-IR axons were not observed in the HPFv (Figure 5a) or in the dorsal HPF (not shown), whereas extensive labeling was observed elsewhere (eg, thalamic paraventricular nucleus; Figure 5b), consistent with previous reports (Gu et al, 2013; Llewellyn-Smith et al, 2011). Notably, we observed GLP-1-IR axon terminals in very close proximity to the ventricular ependyma at several rostral sites, including the paraventricular nucleus thalamus (third 
a

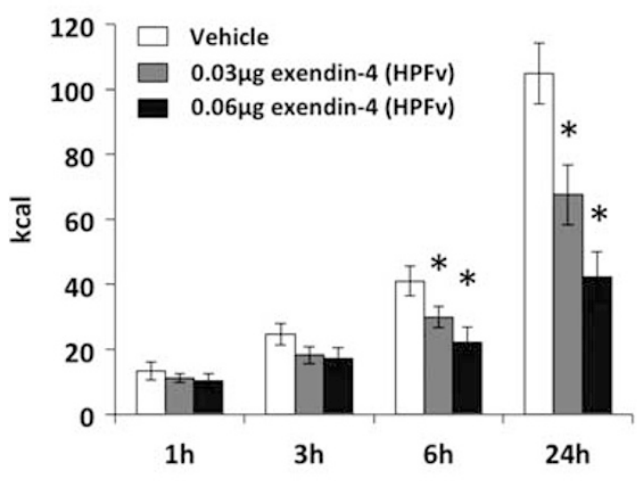

c

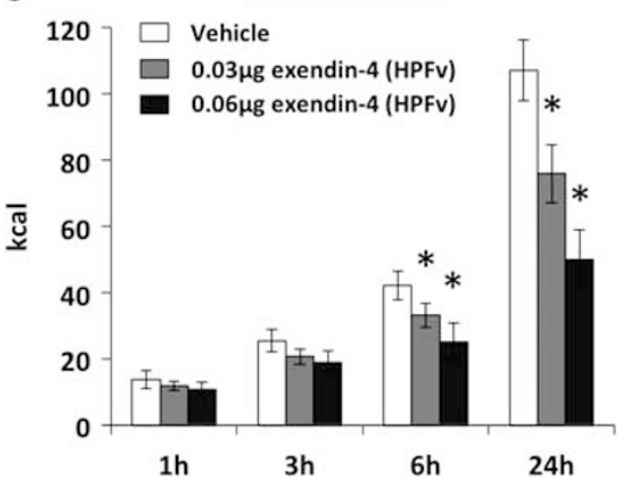

b

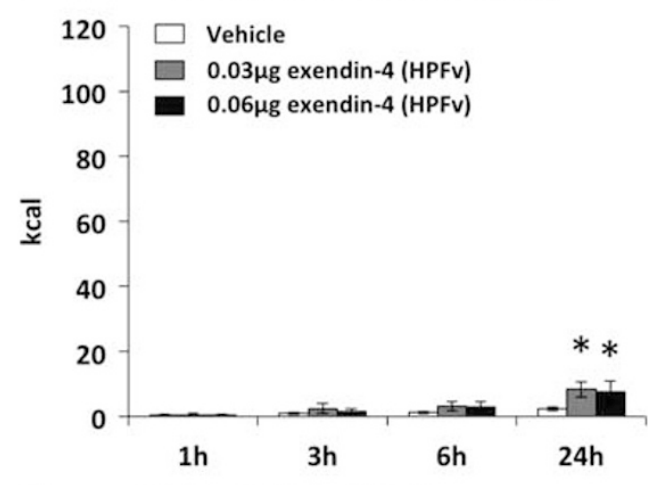

d

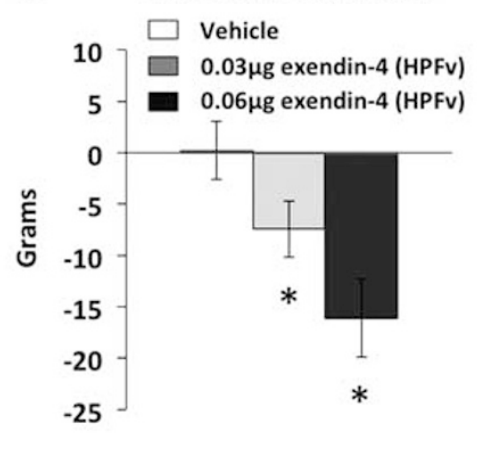

Figure 3 Cumulative intake of, (a) Western diet, (b) chow, (c) total kcal (WD + chow), when given a choice of consuming chow or Western diet, and (d) $24 \mathrm{~h}$ delta body weight following HPFv GLP-IR activation. Data are mean \pm SEM; $* p<0.05$ vs vehicle treatment. WD, Western diet.

a

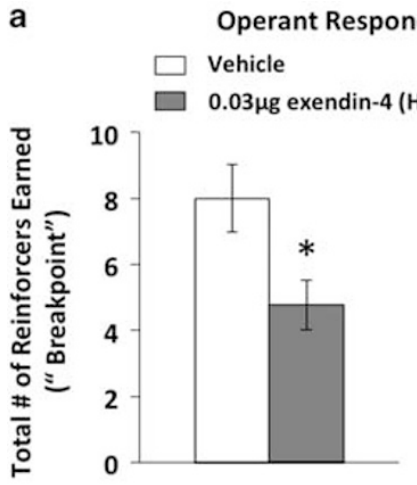

C

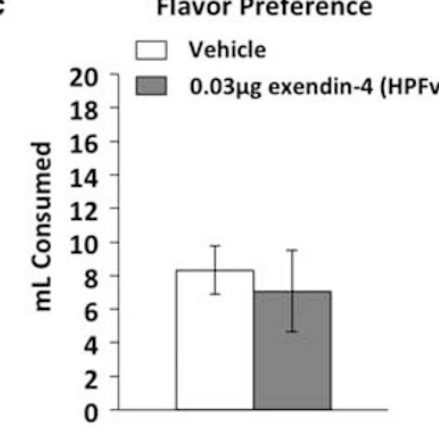

b

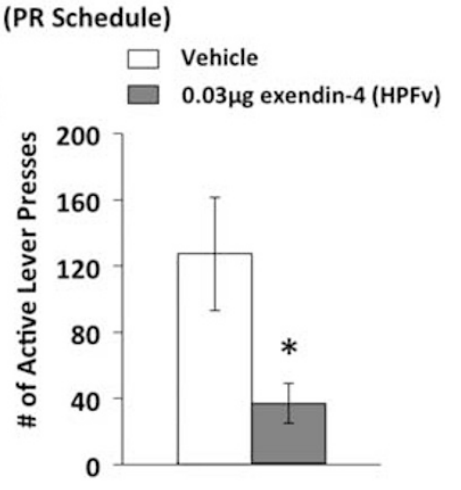

$\begin{aligned} & \text { b } \quad \text { Conditioned Place Preference } \\ & \square \text { Vehicle } \\ & \square \quad 0.03 \mu \mathrm{g} \text { exendin- } 4 \text { (HPFv) }\end{aligned}$

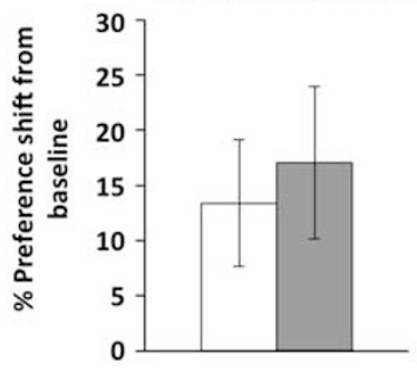

Flavor Preference

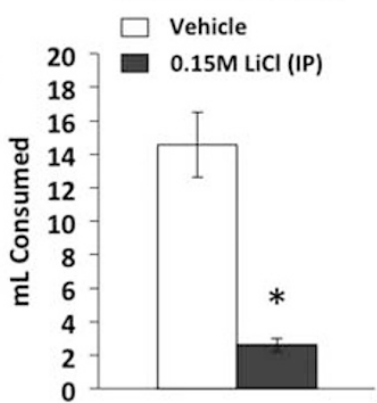

Figure 4 (a) Operant responding (breakpoint and active lever presses) following HPFv GLP-IR activation under a PR reinforcement, and (b) conditioned place preference for food following HPFv exendin-4. (c) 90 min flavor preference tests for conditioned flavor avoidance (CFA) assessment, following HPFv GLP-IR activation or IP LiCl treatment. Data are mean \pm SEM; * $p<0.05$ vs vehicle. 

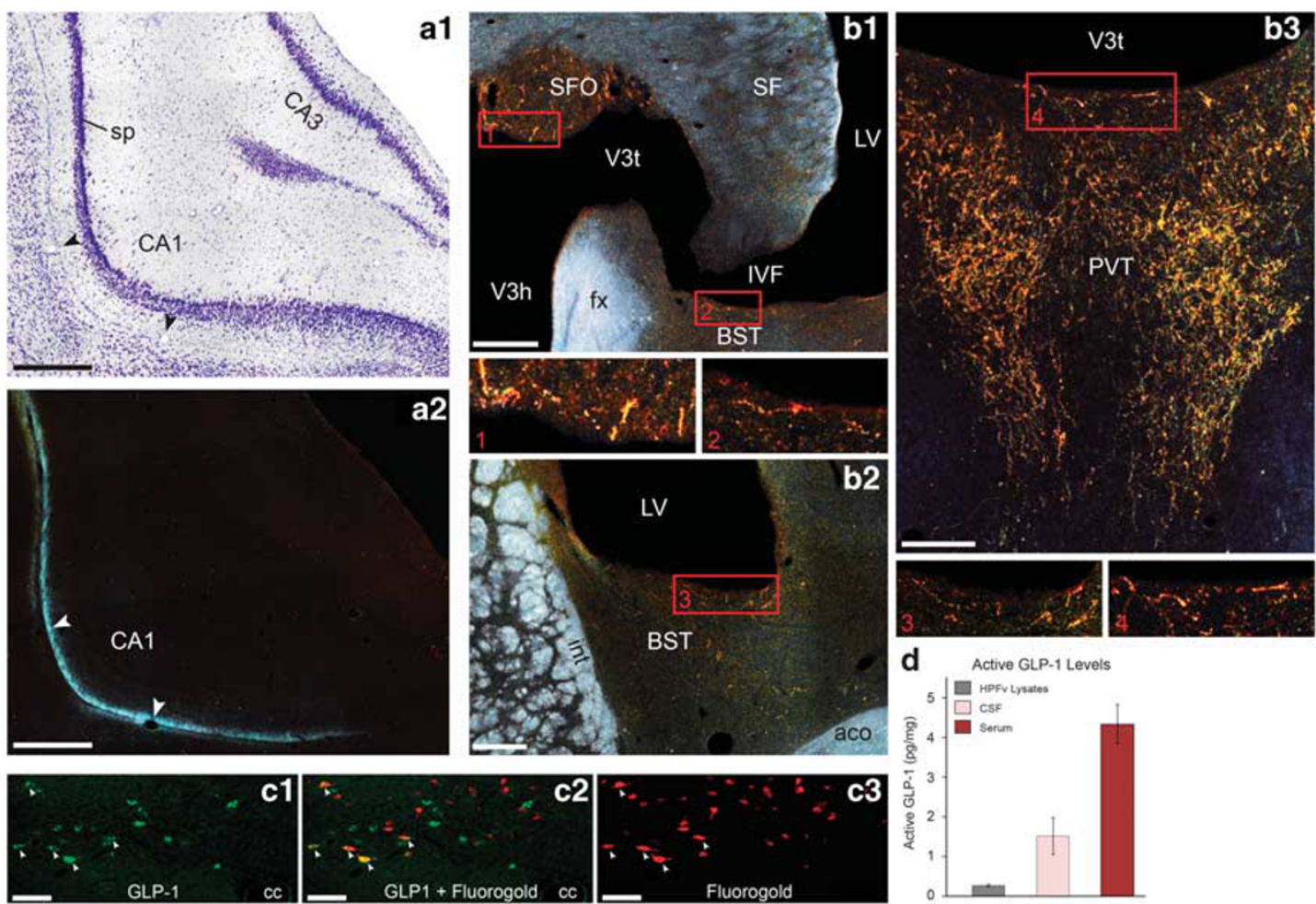

Figure 5 (al-2): Absence of GLP-I immunoreactivity in the hippocampal formation (a representative level of field CAI shown). In the Nissl-stained section (al), the pyramidal layer (sp) is indicated, and arrowheads indicate the position of the alveus in both the Nissl-stained section and an adjacent section (a2) processed for immunohistochemical detection of GLP-I (darkfield illumination). (b I-3): examples of GLP-I-immunoreactive axons in selected brain regions (darkfield illumination), and close apposition of these axons to the cerebral ventricles (insets I-4). (cl-3): GLP-I immunofluorescent neurons (green, $\mathrm{cl}$ and $\mathrm{c2}$ ) in the nucleus tractus solitarius were in some instances found to contain the retrograde tracer fluorogold (red, c2 and c3) following its lateral ventricular injection. Arrowheads in c2 indicate examples of double-labeled perikarya, which show varying levels of additive yellow color (corresponding arrowheads for the single color channels are shown in cl and c3). BST, Bed nuclei stria terminalis; cc, central canal; IVF, interventricular foramen; LV, lateral ventricle; PVT, paraventricular nucleus thalamus; SF, septofimbral nucleus; SFO, subfornical organ; V3h/t, third ventricle hypothalamic/ thalamic part. Bars $=500 \mu \mathrm{M}$ (a I-2); $200 \mu \mathrm{M}$ (b I-3); $100 \mu \mathrm{M}$ (cl-3). (d): Active levels of GLP-I (detected with high sensitivity ELISA) in HPFv lysates, the CSF, and serum.

ventricle), bed nuclei of the stria terminalis (lateral ventricle), and the subfornical organ (interventricular foramen level) (Figure 5b). We therefore tested the hypothesis that neuronal GLP-1 may be released into the ventricular system. Following LV FG injection, we found FG back-labeled perikarya in the NTS, including in some GLP-1-IR neurons (Figure 5c). The percentage of GLP-1-IR perikarya that were co-labeled with FG was quantified in a representative section $(\sim 14.4 \mathrm{~mm}$ posterior to bregma) for each animal; the average \% calculated was $29 \%$. No FG labeling was found in the NTS of a control animal with FG injected into the cingulate cortex overlying the LV.

\section{Experiment 5}

Active GLP-1 was detected in the serum of both groups, as expected. Active GLP-1 levels were also above the lowest threshold of detection (which was $0.14 \mathrm{pM}$ ) in the CSF for each of the four rats in Group 1, and in HPFv lysates for each of the seven rats in Group 2. Values were converted from $\mathrm{pM}$ to picograms of active GLP-1 per milligram of total sample protein (based on Bradford protein assay results) to standardize with active GLP-1 levels in HPFv lysates (Figure 5d). The serum data were pooled from the two groups as there were no significant serum differences between the groups. When adjusted for total protein, active levels were approximately sixfold higher in CSF compared HPFv tissue, and approximately threefold higher in serum compared with CSF under these conditions.

\section{DISCUSSION}

GLP-1R signaling reduces food intake and body weight via action at multiple brain regions, including hypothalamic, hindbrain, and mesolimbic nuclei (for review see Hayes et al, 2014; Skibicka, 2013). Here we show that GLP-1R activation in the HPFv, a telencephalic region traditionally associated with motivation and memory, potently reduces feeding and body weight. Administration of the GLP-1R agonist Exendin-4 to the HPFv reduced chow intake $(\sim 40 \%)$ and body weight at doses that were ineffective when infused in the LV. Furthermore, HPFv administration of the GLP-1R antagonist, exendin-(9-39), increased food intake $(\sim 30 \%) 6 \mathrm{~h}$ after administration, suggesting that HPFv GLP-1R signaling is endogenously relevant to feeding behavior. When rats were given a choice between a high fat 'Western diet' $v s$ less palatable food (standard chow), potent intake reduction of the Western diet was observed, coupled with a small, but significant increase in chow consumption. 
Taken together, these findings suggest that the anorectic effects of endogenous HPFv GLP-1R signaling are applicable to various foods that differ in palatability and macronutrient content, including 'obesogenic' foods that are high in fat and sugar content. It is unclear whether the hypophagic effect of HPFv GLP-1R activation on Western diet intake would be reduced (or have delayed onset) following longerterm Western diet maintenance, as has been previously observed in rodents following peripheral Exendin-4 delivery (Mul et al, 2013; Williams et al, 2011).

The behavioral and physiological mechanisms mediating food intake reduction by HPFv GLP-1R activation were examined using various strategies. First, we demonstrated that HPFv exendin- 4 administration reduced food intake through a specific reduction in meal size with no effect on meal frequency. This is consistent with several other reports showing that either peripheral (Bello et al, 2010; Ruttimann et al, 2009; Scott and Moran, 2007; Thiele et al, 1997) or central (Dossat et al, 2013; Mietlicki-Baase et al, 2013) GLP-1R activation reduces intake primarily via meal size reduction. Further, these results are in line with several recent findings that link neural processing in the hippocampus to satiation control. Neurons in the hippocampus are responsive to various gastrointestinal satiation signals, including gastric distension (Min et al, 2011a), nutrient infusion (Min et al, 2011b), and vagal nerve stimulation (Furmaga et al, 2012). We recently demonstrated that ghrelin receptor signaling in the HPFv increases food intake, in part, by augmenting meal size (Kanoski et al, 2013), which, taken together with the present results, suggests that HPFv neurons influence meal size in a modulatory, bi-directional manner.

To determine whether HPFv GLP-1R-mediated food intake reduction is secondary to nausea, we examined CFA following HPFv exendin-4. Several previous findings have tied peripheral and central administration of GLP-1R ligands to nausea responses in rodents (CFA, pica) (Kanoski et al, 2012; Kinzig et al, 2002; Rinaman, 1999). However, recent data show that endogenous GLP-1R signaling in the VTA (Alhadeff $e t a l, 2012$ ) and nucleus accumbens (Dossat et al, 2011) reduces feeding in the absence of concomitant nausea. Consistent with these findings, our present results revealed no CFA induced by a dose of HPFv exendin- 4 that potently suppressed food intake $(0.03 \mu \mathrm{g})$, suggesting that anorectic effects of HPFv GLP-1R signaling are likely driven by mechanisms other than nausea. Given that the HPFv neurons receive direct innervation from the VTA (Gasbarri et al, 1994), and also monosynaptically project to the nucleus accumbens (Floresco et al, 2001; Groenewegen et al, 1987), the interconnected mesolimbic 'reward' system appears to comprise part of a CNS limbic circuit through which GLP-1R-mediated intake reduction is not a secondary artifact of visceral illness.

We also examined effects on motivational aspects of feeding behavior following HPFv GLP-1R activation using conditioned place preference and PR operant responding behavioral paradigms. HPFv exendin-4 administration did not influence CPP for the palatable food-associated context under testing parameters that did not allow for food consumption. In contrast, $\mathrm{HPFv}$ exendin-4 reduced breakpoint lever press responding under a PR reinforcement schedule, where animals periodically had the opportunity to consume the reinforcer. These data suggest that HPFv GLP-1R signaling acts to decrease motivated responding for palatable food primarily when food consumption is involved during testing. An alternative interpretation is that HPFv GLP-1R signaling differentially impacts the expression of learned associations between contextual cues and food reinforcement (CPP test) vs associations between operant responses and food reinforcement (PR test). When administered peripherally, however, exendin-4 reduces both the expression of CPP and breakpoint PR operant responding (Dickson et al, 2012). It is possible that HPFv exendin-4 would also reduce CPP under different testing conditions (eg, higher dose, different injection timing). However, given that the CPP testing conditions closely paralleled those of the PR test, the data support a differential impact of HPFv GLP-1R activation on the expression of these two distinct food-motivated learned behaviors. When considered together with our reduced meal size effect results, it appears that GLP-1R signaling in the $\mathrm{HPFv}$ reduces intake, at least in part, via post-ingestive mechanisms involving amplification of satiation and satiety-promoting effects of various prandial and postprandial biological signals.

The source for endogenous GLP-1 ligands that act on $\mathrm{HPFv}$ receptors is unknown. Our IHC analyses confirmed the absence of GLP-1 axons in the HPF (Figure 5a; Gu et al, 2013; Llewellyn-Smith et al, 2011), suggesting that HPF GLP-1R activation occurs via a non-synaptic route. One possibility is that intestinally-derived GLP-1 enters the vasculature and crosses the blood brain barrier to reach HPFv GLP-1R's. Indeed, GLP-1 does readily cross the blood brain barrier (Kastin et al, 2002); however, owing to the rapid enzymatic degradation of GLP-1 in peripheral circulation (Holst, 2007), more work is needed to determine the biological relevance of peripheral-to-CNS GLP-1 physiology. A novel possible route suggested by present data is that neuronal GLP-1 reaches the HPF after its release into the ventricular system. Following FG injection into the rostral LV, we observed FG back-labeled perikarya in the NTS, including $\sim 30 \%$ of GLP-1-IR neurons (Figure $5 \mathrm{c}$ ). In addition, we observed GLP-1-IR axon terminals in very close proximity to the ventricular ependyma (Figure 5b), including sites rostral to the HPF (which is notable given the rostral-caudal flow of CSF). We note a caveat in that we cannot rule out the possibility that FG back-labeling of NTS neurons occurred as a result of diffusion of FG from ventricles into the neuropil. However, this novel result, taken together with our observation of ventricular-apposed GLP-1R axons, raises the possibility of a non-synaptic route, whereby neuronal GLP-1 may reach GLP-1Rs expressed in the HPFv and other nuclei. Although there is considerable evidence supporting the existence of CSF-mediated 'volume' neurotransmission for other neuropeptidergic systems (for review, see Vigh et al, 2004); to our knowledge this possibility has not been previously investigated for GLP-1 neurons.

Additional support for CSF volume transmission as a mechanism for HPFv GLP-1 signaling is provided by our results detecting the presence of active GLP- 1 in the CSF of rats under physiological conditions (Figure 5d). Previous studies have detected active GLP-1 in the CSF of rats (Heile et al, 2009) and cats (Glage et al, 2011), however, in these 
studies active GLP-1 was only observed following the cerebral implantation of encapsulated mesenchymal stem cells and was below the threshold for detection in control groups. Here we used a higher sensitivity GLP-1 ELISA assay compared with these previous reports, and not only did we observe the presence of active GLP-1 in the CSF, but also in HPFv lysates (at $\sim 1 / 6$ the concentration in CSF). Taken together with our results suggesting that CNSderived GLP-1 may access the ventricular system, present data strongly support CSF volume transmission as a physiological mechanism for HPFv (and CNS more generally) GLP-1R signaling. Future studies are needed to determine the source (peripheral, NTS neurons, or both) of active GLP-1 in the CSF and HPFv, and whether CNS and HPFv GLP-1 levels are influenced by feeding and/or energy status.

Recent findings show that HPFv neuronal processing regulates both anorectic and orexigenic aspects of feeding behavior via peripherally derived neuroendocrine signals (Kanoski et al, 2013, 2011b). Present data extend this work and show that GLP-1 acts on receptors in the HPFv to potently reduce food intake independent of producing nausea, and these anorectic effects are likely to occur, in part, through the amplification of post-ingestive satiation signals. Taken together with our previous work and other recent data linking the dorsal HPF with meal onset and meal size (Henderson et al, 2013), these results highlight the HPF as an emerging brain region of importance in the higherorder control of feeding behavior. HPF neurons are necessary for remembering features of both the external and the internal contextual environment (Kennedy and Shapiro, 2004; Maren and Holt, 2000). Regarding the latter, our overarching hypothesis is that HPF neural processing integrates interoceptive 'contextual' information relevant to energy status with previous learned experiences to influence both appetitive and consummatory aspects of feeding behavior. One mechanism through which the internal context is communicated to the HPF is through endocrine signals whose circulating levels are influenced by energy status (eg, leptin, ghrelin, GLP-1).

In conclusion, present data further substantiate a critical role for the HPF in feeding behavior, and also complement several recent reports (eg, Alhadeff et al, 2012; Dickson et al, 2012; Dossat et al, 2011) in showing that CNS GLP-1R signaling influences feeding via action not only on receptors expressed in traditional feeding centers (ie, hypothalamus and caudal brainstem), but also in various midbrain and forebrain nuclei that control learned and motivational behaviors.

\section{FUNDING AND DISCLOSURE}

The authors declare no conflict of interest. This work was supported by the National Institutes of Health Grants DK097147 and DK102478 (SEK), pilot grant funding from the USC Diabetes and Obesity Research Institute (SEK and JDH), and institutional support from USC Dornsife (SEK).

\section{ACKNOWLEDGEMENTS}

We thank the following individuals for notable contributions to this work: Dr Alan G Watts, Dr Larry W Swanson,
Dr Ruth I Wood, Dr Harvey J Grill, Dr Matthew R Hayes, Hrant Gevorgian, Trosdamad Missaelian, Lilly Taing, Joanna Liang, Jessica Thai, Ryan Usui, Emily Nakamoto, and Mehul Trivedi.

\section{REFERENCES}

Alhadeff AL, Rupprecht LE, Hayes MR (2012). GLP-1 neurons in the nucleus of the solitary tract project directly to the ventral tegmental area and nucleus accumbens to control for food intake. Endocrinology 153: 647-658.

Azzara AV, Sokolnicki JP, Schwartz GJ (2002). Central melanocortin receptor agonist reduces spontaneous and scheduled meal size but does not augment duodenal preload-induced feeding inhibition. Physiol Behav 77: 411-416.

Bello NT, Kemm MH, Ofeldt EM, Moran TH (2010). Dose combinations of exendin-4 and salmon calcitonin produce additive and synergistic reductions in food intake in nonhuman primates. Am J Physiol Regul Integr Comp Physiol 299: R945-R952.

Davidson TL, Kanoski SE, Schier LA, Clegg DJ, Benoit SC (2007). A potential role for the hippocampus in energy intake and body weight regulation. Curr Opin Pharmacol 7: 613-616.

Davidson TL, Kanoski SE, Walls EK, Jarrard LE (2005). Memory inhibition and energy regulation. Physiol Behav 86: 731-746.

Dickson SL, Shirazi RH, Hansson C, Bergquist F, Nissbrandt H, Skibicka KP (2012). The glucagon-like peptide 1 (GLP-1) analogue, exendin-4, decreases the rewarding value of food: a new role for mesolimbic GLP-1 receptors. I Neurosci 32: 4812-4820.

Dossat AM, Diaz R, Gallo L, Panagos A, Kay K, Williams DL (2013). Nucleus accumbens GLP-1 receptors influence meal size and palatability. Am J Physiol Endocrinol Metab 304: E1314-E1320.

Dossat AM, Lilly N, Kay K, Williams DL (2011). Glucagon-like peptide 1 receptors in nucleus accumbens affect food intake. J Neurosci 31: 14453-14457.

During MJ, Cao L, Zuzga DS, Francis JS, Fitzsimons HL, Jiao X et al (2003). Glucagon-like peptide-1 receptor is involved in learning and neuroprotection. Nat Med 9: 1173-1179.

Floresco SB, Todd CL, Grace AA (2001). Glutamatergic afferents from the hippocampus to the nucleus accumbens regulate activity of ventral tegmental area dopamine neurons. J Neurosci 21: 4915-4922.

Furmaga H, Carreno FR, Frazer A (2012). Vagal nerve stimulation rapidly activates brain-derived neurotrophic factor receptor TrkB in rat brain. PLoS One 7: e34844.

Gasbarri A, Verney C, Innocenzi R, Campana E, Pacitti C (1994). Mesolimbic dopaminergic neurons innervating the hippocampal formation in the rat: a combined retrograde tracing and immunohistochemical study. Brain Res 668: 71-79.

Glage S, Klinge PM, Miller MC, Wallrapp C, Geigle P, Hedrich HJ et al (2011). Therapeutic concentrations of glucagon-like peptide-1 in cerebrospinal fluid following cell-based delivery into the cerebral ventricles of cats. Fluids Barriers CNS 8: 18.

Groenewegen HJ, Vermeulen-Van der Zee E, te Kortschot A, Witter MP (1987). Organization of the projections from the subiculum to the ventral striatum in the rat. A study using anterograde transport of Phaseolus vulgaris leucoagglutinin. Neuroscience 23: 103-120.

Gu G, Roland B, Tomaselli K, Dolman CS, Lowe C, Heilig JS (2013). Glucagon-like peptide-1 in the rat brain: distribution of expression and functional implication. J Comp Neurol 521: 2235-2261.

Hayes MR, Leichner TM, Zhao S, Lee GS, Chowansky A, Zimmer D et al (2011). Intracellular signals mediating the food 
intake-suppressive effects of hindbrain glucagon-like peptide-1 receptor activation. Cell Metab 13: 320-330.

Hayes MR, Mietlicki-Baase EG, Kanoski SE, De Jonghe BC (2014). Incretins and Amylin: neuroendocrine communication between the gut, pancreas, and brain in control of food intake and blood glucose. Annu Rev Nutr 34: 237-260.

Hayes MR, Skibicka KP, Grill HJ (2008). Caudal brainstem processing is sufficient for behavioral, sympathetic, and parasympathetic responses driven by peripheral and hindbrain glucagon-like-peptide-1 receptor stimulation. Endocrinology 149: 4059-4068.

Heile AM, Wallrapp C, Klinge PM, Samii A, Kassem M, Silverberg $\mathrm{G}$ et al (2009). Cerebral transplantation of encapsulated mesenchymal stem cells improves cellular pathology after experimental traumatic brain injury. Neurosci Lett 463: $176-181$.

Henderson YO, Smith GP, Parent MB (2013). Hippocampal neurons inhibit meal onset. Hippocampus 23: 100-107.

Holst JJ (2007). The physiology of glucagon-like peptide 1. Physiol Rev 87: 1409-1439.

Kanoski SE (2012). Cognitive and neuronal systems underlying obesity. Physiol Behav 106: 337-344.

Kanoski SE, Alhadeff AL, Fortin SM, Gilbert JR, Grill HJ (2014). Leptin signaling in the medial nucleus tractus solitarius reduces food seeking and willingness to work for food. Neuropsychopharmacology 39: 605-613.

Kanoski SE, Fortin SM, Arnold M, Grill HJ, Hayes MR (2011a). Peripheral and central GLP-1 receptor populations mediate the anorectic effects of peripherally administered GLP-1 receptor agonists, liraglutide and exendin-4. Endocrinology 152: 3103-3112.

Kanoski SE, Fortin SM, Ricks KM, Grill HJ (2013). Ghrelin Signaling in the Ventral Hippocampus Stimulates Learned and Motivational Aspects of Feeding via PI3K-Akt Signaling. Biol Psychiatry 73: 915-923.

Kanoski SE, Hayes MR, Greenwald HS, Fortin SM, Gianessi CA, Gilbert JR et al (2011b). Hippocampal leptin signaling reduces food intake and modulates food-related memory processing. Neuropsychopharmacology 36: 1859-1870.

Kanoski SE, Rupprecht LE, Fortin SM, De Jonghe BC, Hayes MR (2012). The role of nausea in food intake and body weight suppression by peripheral GLP-1 receptor agonists, exendin-4 and liraglutide. Neuropharmacology 62: 1916-1927.

Kastin AJ, Akerstrom V, Pan W (2002). Interactions of glucagonlike peptide-1 (GLP-1) with the blood-brain barrier. $J \mathrm{Mol}$ Neurosci 18: 7-14.

Kennedy PJ, Shapiro ML (2004). Retrieving memories via internal context requires the hippocampus. J Neurosci 24: 6979-6985.

Kinzig KP, D'Alessio DA, Seeley RJ (2002). The diverse roles of specific GLP-1 receptors in the control of food intake and the response to visceral illness. J Neurosci 22: 10470-10476.

Larsen PJ, Tang-Christensen M, Holst JJ, Orskov C (1997). Distribution of glucagon-like peptide-1 and other preproglucagon-derived peptides in the rat hypothalamus and brainstem. Neuroscience 77: 257-270.

Llewellyn-Smith IJ, Reimann F, Gribble FM, Trapp S (2011). Preproglucagon neurons project widely to autonomic control areas in the mouse brain. Neuroscience 180: 111-121.

Lucas F, Sclafani A (1996). Capsaicin attenuates feeding suppression but not reinforcement by intestinal nutrients. Am J Physiol 270(5 Pt 2): R1059-R1064.

Maren S, Holt W (2000). The hippocampus and contextual memory retrieval in Pavlovian conditioning. Behav Brain Res 110: $97-108$

McClean PL, Parthsarathy V, Faivre E, Holscher C (2011). The diabetes drug liraglutide prevents degenerative processes in a mouse model of Alzheimer's disease. J Neurosci 31: 6587-6594.
McMahon LR, Wellman PJ (1998). PVN infusion of GLP-1-(7-36) amide suppresses feeding but does not induce aversion or alter locomotion in rats. Am J Physiol 274(1 Pt 2): R23-R29.

Merchenthaler I, Lane M, Shughrue P (1999). Distribution of prepro-glucagon and glucagon-like peptide-1 receptor messenger RNAs in the rat central nervous system. J Comp Neurol 403: 261-280.

Mietlicki-Baase EG, Ortinski PI, Rupprecht LE, Olivos DR, Alhadeff AL, Pierce RC et al (2013). The food intake-suppressive effects of glucagon-like peptide-1 receptor signaling in the ventral tegmental area are mediated by AMPA/kainate receptors. Am J Physiol 305: E1367-E1374.

Min DK, Tuor UI, Chelikani PK (2011a). Gastric distention induced functional magnetic resonance signal changes in the rodent brain. Neuroscience 179: 151-158.

Min DK, Tuor UI, Koopmans HS, Chelikani PK (2011b). Changes in differential functional magnetic resonance signals in the rodent brain elicited by mixed-nutrient or protein-enriched meals. Gastroenterology 141: 1832-1841.

Mul JD, Begg DP, Barrera JG, Li B, Matter EK, D’Alessio DA et al (2013). High-fat diet changes the temporal profile of GLP-1 receptor-mediated hypophagia in rats. Am J Physiol Regul Integr Comp Physiol 305: R68-R77.

Parent MB, Darling JN, Henderson YO (2014). Remembering to Eat: Hippocampal Regulation of Meal Onset. Am J Physiol Regul Integr Comp Physiol 306: R701-R713.

Pegg CC, He C, Stroink AR, Kattner KA, Wang CX (2010). Technique for collection of cerebrospinal fluid from the cisterna magna in rat. J Neurosci Methods 187: 8-12.

Perry T, Haughey NJ, Mattson MP, Egan JM, Greig NH (2002). Protection and reversal of excitotoxic neuronal damage by glucagon-like peptide-1 and exendin-4. J Pharmacol Exp Ther 302: 881-888.

Perry T, Lahiri DK, Sambamurti K, Chen D, Mattson MP, Egan JM et al (2003). Glucagon-like peptide-1 decreases endogenous amyloid-beta peptide (Abeta) levels and protects hippocampal neurons from death induced by Abeta and iron. J Neurosci Res 72: 603-612.

Rinaman L (1999). Interoceptive stress activates glucagon-like peptide-1 neurons that project to the hypothalamus. Am J Physiol 277(2 Pt 2): R582-R590.

Ritter RC, Slusser PG, Stone S (1981). Glucoreceptors controlling feeding and blood glucose: location in the hindbrain. Science 213: 451-452.

Ruttimann EB, Arnold M, Hillebrand JJ, Geary N, Langhans W (2009). Intrameal hepatic portal and intraperitoneal infusions of glucagon-like peptide-1 reduce spontaneous meal size in the rat via different mechanisms. Endocrinology 150: 1174-1181.

Schick RR, Zimmermann JP, vorm Walde T, Schusdziarra V (2003). Peptides that regulate food intake: glucagon-like peptide 1-(7-36) amide acts at lateral and medial hypothalamic sites to suppress feeding in rats. Am J Physiol Regul Integr Comp Physiol 284: R1427-R1435.

Scott KA, Moran TH (2007). The GLP-1 agonist exendin-4 reduces food intake in nonhuman primates through changes in meal size. Am J Physiol Regul Integr Comp Physiol 293: R983-R987.

Shirazi R, Palsdottir V, Collander J, Anesten F, Vogel H, Langlet F et al (2013). Glucagon-like peptide 1 receptor induced suppression of food intake, and body weight is mediated by central IL-1 and IL-6. Proc Natl Acad Sci USA 110: 16199-16204.

Skibicka KP (2013). The central GLP-1: implications for food and drug reward. Front Neurosci 7: 181.

Thiele TE, Van Dijk G, Campfield LA, Smith FJ, Burn P, Woods SC et al (1997). Central infusion of GLP-1, but not leptin, produces conditioned taste aversions in rats. Am J Physiol 272(2 Pt 2): R726-R730. 
Turton MD, O'Shea D, Gunn I, Beak SA, Edwards CM, Meeran K et al (1996). A role for glucagon-like peptide-1 in the central regulation of feeding. Nature 379: 69-72.

Vigh B, Manzano e Silva MJ, Frank CL, Vincze C, Czirok SJ, Szabo A et al (2004). The system of cerebrospinal fluidcontacting neurons. Its supposed role in the nonsynaptic signal transmission of the brain. Histol Histopathol 19: 607-628.

Vrang N, Hansen M, Larsen PJ, Tang-Christensen M (2007). Characterization of brainstem preproglucagon projections to the paraventricular and dorsomedial hypothalamic nuclei. Brain Res 1149: $118-126$.

Williams DL, Baskin DG, Schwartz MW (2009). Evidence that intestinal glucagon-like peptide-1 plays a physiological role in satiety. Endocrinology 150: 1680-1687.

Williams DL, Hyvarinen N, Lilly N, Kay K, Dossat A, Parise E et al (2011). Maintenance on a high-fat diet impairs the anorexic response to glucagon-like-peptide-1 receptor activation. Physiol Behav 103: 557-564. 